International Journal of Life Sciences
Available online at http://sciencescholar.us/journal/index.php/ijls
Vol. 2 No. 3, December 2018, pages: 38 47
e-ISSN: 2550-6986, p-ISSN: 2550-6994
https://doi.org/10.29332/ijls.v2n3.202

\title{
Flower Growth Position Determines with Formation of Fruit-set on Citrus Siam Plants
}

\author{
Ni Putu Anom Sulistiawati a
}

Article history: Received 21 July 2018, Accepted: 30 August 2018, Published: 2 October 2018

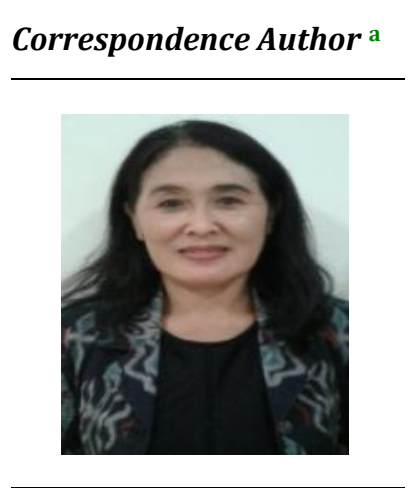

Keywords

Citrus siam plants;

Endogenous;

Environment;

Fallen;

Fruit-se;

\begin{abstract}
The purpose of this study was to find out the position of the emergence of flowers associated with the formation of fruit-set as a potential fruit on the citrus Siam plant. This study used a randomized block design with two factors observed that is flower position on the branch and flowering period. The results of the statistic data tabulation show that. The interaction between the positions of the flowering period on citrus Siam plants is not significantly different. The position of the emergence of the flower determines many fruitset are formed. Top branch. The position of the top branch shows the percentage of fruit-set is formed more that is $97,95 \%$ and the lowest in rootstock, that is 91,30 . This incident was supported by more interest formed when the top branch that's is 224,95 florets more $53,65 \%$ if it is stretched in the lower stem position 104,27 florets. This is supported by relative water content, chlorophyll, N, P, K and sucrose leaves i.e. 46,78 \%, 28,82 \%, 1,40\%, $0,74 \%, 3,42 \%$ and $3,42 \%$ bigger than the lower stem i.e. $41,36 \%, 18,64 \%$, $1,16 \%, 0,19 \%$, and $2,17 \%$.
\end{abstract}

e-ISSN: 2550-6986, p-ISSN: 2550-6994@ Copyright 2018. The Author. SS Journals Published by Universidad Técnica de Manabí. This is an open-access article under the CC BY-SA 4.0 license (https://creativecommons.org/licenses/by-sa/4.0/) All rights reserved.

\section{Contents}

Abstract

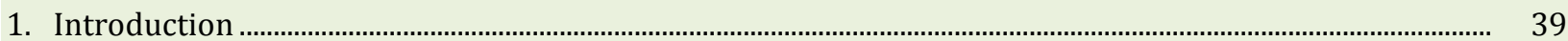

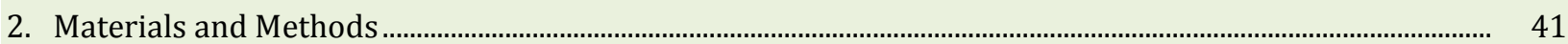

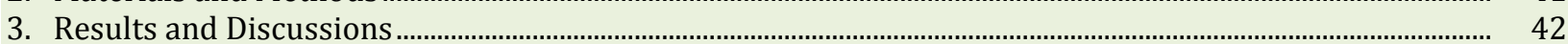

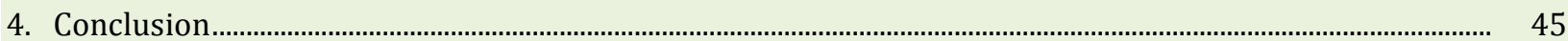

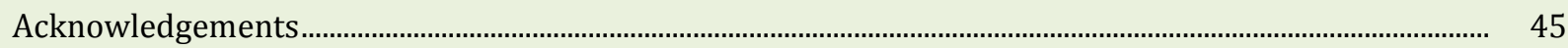

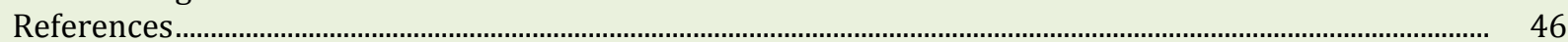

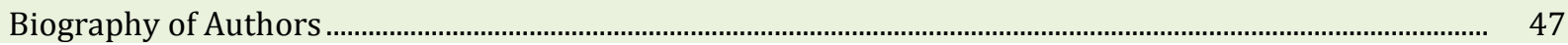

a Agrotechnology, Faculty of Agriculture, Warmadewa University, Indonesia 


\section{Introduction}

Fruit plant interpret the cue for its growth are largely determined by the environmental and endogenous factors of the fruit plant. In the phenomenon of fruit - set formed on the oranges (Citrus nobilis, Var microcarpa $\mathrm{L}$ ) is a very phenomenon that the unit still needs a deeper assessment. Flowering transitions are key factors that determine fruit productivity (Parvathi et al., 2014). The flowering phenomenon of fruit plants is a complex event, which morphologically changes from the vegetative phase to the reproductive phase. At the start of the flowering, there is a transition from a relatively simple leaf structure to a more complex flower structure. It begins with the diffuse meristem forming leaflet and began producing flower organ (Nazeer et al., 2014).

The citrus plant is a plant with seasonal flowering and seasonal properties. Orange cultivation is known for its very short period of time so it has a juvenile period or plant age to produce long flowering. Its bloom is often encountered because it requires special requirements for can be induced in flowering and fruiting (Reddy, 2014). The orange plants come from the shoots/armpits that have previously undergone dormancy. Generally, most plants, after flower development develops, the ovaries begin to grow and begin to grow. This usually coincides with the fall and fall of a flower jewelry like a petal. The occurrence of these changes indicates the occurrence of the transition from the flower to the young by (Rai, 2010) referred to as fruit-sets, while according to (Rai et al., 2010) the fruit-set is the proportion of fixed flowers survived after the falling petals.

The number of flowers produced by orange plants is determined by the shoot/ plant because of the flowering properties of the terminals Siam plants that grow and appear only from the tip of the shoots. Furthermore, the intensity of pollination and fertilization does not affect the amount of fruit that can be harvested. So the number of harvesting in orange plants is determined by the number of flowering shoots and the ability of the plants to maintain that the flowers and fruits do not fall. Fruit plants have two flower conditions or fruit miscarriage: (1) flowers and fruits in normal condition, when fall does not show signs of damage to the base and (2) flowers or fallen fruit are damaged at the base due to physiological or 9genetic effects, and miscarriage accompanied by damage to the base caused by disturbances from disturbing organisms (Rai et al, 2010)

The physiology of the fall of flowers or fruits is correlated with limited supply of photosynthetic and nutrient sufficiency in fruit plants (Rai et al., 2016), as well as the occurrence of hormonal regulation in the transition zone (Parvanti, 2014), this is in line with the results of the research conducted on plants Cashew nuts (Saroj et al., 2014) The fall of flowers and fruits is largely determined by the low supply of photosynthesis. From the observations conducted in Catur Village that the amount of fruit that can be harvested very little because of the number of flowers and fallen fruit, it has not been known for any cause so there is no control recommendation that can be put in the field. In the flowering season, often the shoots or armpits that have been fruiting during the fruiting season can not be flowered in the next season.

The important problems are confronted by citrus growers, so it is not guaranteed the continuity of production and high production fluctuations during the harvest season. In the harvest season or at the time of the fruit production period, on the contrary, when the number of fruit is very limited, there is almost no harvest but the cost of the fruit is expensive. That situation causes low farmer income so less enthusiasm to cultivate its plants intensively. Given the nature of the tropical fruit plants, it is generally the alternate bearing, as a result of flowering, not all bada trees survive in the tree to be fruit-set, in other words in one plant at the same time there are flowering armpits survive and fall from the shoots of the oranges. Based on these problems then:

1) Is the same as the endogenous content of flower plants formed and occurs in the fall flower in the oranges?

2) Is there any influence of endogenous sources on plants that can determine the development of the flower can survive until it can be formed of fruit-set on the oranges

Sulistiawati, N. P. A. (2018). Flower growth position determines with formation of fruit-set on citrus siam plants. International Journal of Life Sciences, 2(3), 38-47. https://doi.org/10.29332/ijls.v2n3.202 
Research Objectives

Based on the above-mentioned problems, the objectives of this study are:

1) General Purpose

Finding a model for making flowers can be formed into a fruit-set in order to develop the added value of producing quality and sustainable fruits.

2) Special Purpose

a) Different changes in the content of endogenous substances that cause the flowers to survive in the oranges.

b) The design of a model of the factor causing the orange plantation drops and can survive until the formation of fruit-set.

\section{Library Review}

When the plant reaches its reproductive development stage, some or all of the apex shoots/aphrodite meristem stop producing leaves and begin to form flower parts in order of the typical species (Reddy, 2014). Unlike the leaf formation that meristem apexes extend back during one plastocrine, in the formation of flowers, broadly apex leaf apex reduces when flower parts are formed sequentially. Most plant species, the order of formation of flower parts go from outside to inside from sepals (calyx), petal (corolla), varnish (statemen) and bud (pistil) (Rai et al., 2010). A similar opinion was suggested (Sulistiawati and Kartini, 2016) that flowers can be regarded as a branch of limited growth, short-lived, and their leaves have changed shape. The first leaf line (formed below the bottom) is usually green, called calyx, the second leaf series is located above it, it looks more subtle, wider and more beautifully colored, named crown or crown (corolla), the third leaf chain rolled is called the four strands of silk and the fourth row of layers, which is located at the top (the most end) of the attachment to the one called the bud (pistil). The branch with the leaves that have changed its shape is called Flowers receptaculum) is the tip of the flower stalk that usually widens. Apex reproductive that produce flowers usually develop from the vegetative apex, which produces vegetative shoots. The vegetative apex function is to produce the axis growth in the longitudinal direction, while the reproductive apex function is to form a wider area of meristematic, where the various flower parts develop (Reddy, 2014).

After the plant reaches its reproductive development stage, some or all of the apex meristem on the branches stop producing leaves and begin to form flower parts in order of the typical species (Reddy, 2014). Different from the formation of leaves that aphid the apex are spread over one plastocrine, on the formation of flowers, broadly apex leaf apex reduces as the flower parts are formed sequentially. Most plant species, the order of formation of flower parts go from outside to inside from sepals (calyx), petal (corolla), varnish (statemen) and bud (pistil) (Rai et al., 2010).

Flowering physiology in fruit plants according to Nazer (2014) is seen from perennial temperate regions that flowers can be regarded as a branch of limited growth, short-lived, and the leaves have changed shape. The first leaf line (formed below the bottom) is usually green, called calyx, the second leaf series is located above it, it looks more subtle, wider and more beautifully colored, named crown or crown (corolla), the third leaf chain rolled is called the four strands of silk and the fourth row of layers, which is located at the top (the most end) of the attachment to the one called the bud (pistil). The branch with the leaves that have changed its shape is called Flowers. Receptaculum is the tip of the flower stalk that usually widens.

The flowering process, which starts when the dormant leaves are induced into flowers, often do not occur on the entire plant underparts. The flowering process contains a number of important stages, all of which must be successful in obtaining fruit. Each stage is affected by endogenous plant and plant exogenous factors (Hovarth, 2009).

According to Kowalska (2008), stages of flower development include flower induction (avocation), flower initiation, flower bud development to anthesis. The achievement of the stage of reproductive development phase in the plant is characterized by some or all of the apex meristem shoots on the branch ceasing to produce leaves, and the flowers begin to form in accordance with their typical order in accordance with the species of the plant. In most types of fruit plants, the order of formation of flower parts takes place from 
outside to inside ranging from sepals (calyx), petals (corolla), stamens (stamens) and buds (pistils) (Hovarth, 2009)

\section{Materials and Methods}

Place and Time

The research plan is based on Chess, Kintamani District, Bangli Regency in 2017. Catur Village is located 12 $\mathrm{km}$ northwest of Kintamani Subdistrict, located at an altitude of 1250 meters above sea level with a total area of 746 Ha land divided into 630,25 Ha dry land, 2 Materials, and Tools. The orange plants that are being studied are those who are 10 years old, as many as 10 plants from the expanse of farmer's farm. Citrus plants have been preserved in the manner of farmer cultivation, in accordance with the real condition of the field. Farmer's way of cultivation is cultivated with organic fertilizers and irrigation only from rainfall. Routine maintenance is just an eradication of fungal diseases on the bark of citrus stems by wearing Alika disease with 1-2 ml/liter dosage of water and for the prevention of pests it is usually used by Syngenta with a dose of 0.2 $0.4 \mathrm{ml} /$ liter of water, cleaning weeds around trees, and trimming branches that have been worn, twigs are burned and then dumped people's plantation covering an area of $320 \mathrm{Ha}$ and 60 hectares of forest

\section{Research procedures}

The implementation was carried out in the field and in the laboratory on orange plants as many as 10 plants taken randomly from 36 plants used as research. The research was carried out in two stages, namely in the early research (first year), the research was conducted to identify the shoots that could be flowering, and not flowering, the second phase is: how plants can be induced flowering and the flower can survive until the formation of fruit-set.

a) Sample collection and direct observation of morphological aspects of fall flowers and flowers do not fall. Flowers are categorized successfully with fruit-set when the petals fall, the flowers still survive in the trees, in other words, do not suffer from miscarriage. For the size of the fruit is restricted to the size of the pentel at that time about $1 \mathrm{~cm}$. The observation was carried out on the aspect of flower and nipple growth

b) Research at the Laboratory for observation of changes in endogenous content in shoots whose flowers and the fruit and the shoots remain in the tree through the analysis of endogenous contents contained.

\section{Research Design}

This research uses Environmental Random Design with a non-free variable factor wi15 replications (from 10 plants). Factors as non-free variables are flowering periods consisting of two levels: flowering shoots and flowering shoots. This initial study did not use certain treatments, focused only on the identification of endogenous content and the development of flower organ in the saplings and the role of the environment in the flowering.

\section{Variables Observed}

Observation in the field is the growth of flowers and fruits observed include:

a) Long or long flowering period, this is calculated since the first flower appears on the tree until the emergence of the last flower.

b) The amount of interest includes the amount of interest formed and the number of fallen flowers per plant

Sulistiawati, N. P. A. (2018). Flower growth position determines with formation of fruit-set on citrus siam plants. International Journal of Life Sciences, 2(3), 38-47. https://doi.org/10.29332/ijls.v2n3.202 
c) The number of fruit includes large number of fruit and fruit per plant

d) Percentage of Fruit-sets, calculated by dividing the number of flowers that develop into fruit with the number of flowers formed multiplied by $100 \%$.

Laboratory observations include: measuring endogenous plant contents. The endogen content measured include hormone content, total sugar, reduction sugar, sucrose, nutrients $\mathrm{N}, \mathrm{P}, \mathrm{K}$, and C: N ratio. Hormone content analyzed were flowers and fruits as well as flowers and fruit did not fall at the same time. While the total sugar content, reduction sugar, sucrose content $\mathrm{N}, \mathrm{P}$, and $\mathrm{K}$ were analyzed from leaf samples, ie terminal leaves on shoots whose flowers and fruits fall and flowers and fruits did not fall at the same age. N, P, K Terminal leaves. The morphologically observed example is then the separated into terminal leaves and twig peaks under the last segment for analysis of endogenous plant contents

The hormonal analysis follows the Barendse method (1997), conducted at Udayana Horticultural Research Laboratory. At the time of sampling of flowers and fallen fruit and flowers and fruit did not fall off, instances were immediately put into a refrigerated ice box and then dried with a freeze dryer (freeze-dry). After that the samples are stored in the freezer cabinet at $-20 \mathrm{oC}$, then finely pounded and analyzed. Analyzes are done quantitatively with HPLC through several stages of work namely extraction, dilution, purification and measurement with HPLC. Gibberellins analysis uses methanol and acetic phase (60: 40), C-18 stationary phase, 1-mph in-phase flow velocity, the pressure at 900 psi injection and detected with the UV-VIS detector model 440. Measurement Gibberellins content at a wavelength of $210 \mathrm{~nm}$. The method of quantization : the area of the sample is divided by the area of the standard area multiplied by the standard concentration

Total Sugar Content, reducing sugars, and leaf sucrose (mg/g dry weight) were analyzed to identify the photosynthesis as well as to induce the occurrence of flowers. The analysis was done at Laboratory of Agricultural Product Technology, Agricultural Technology, Warmadewa University. Total sugar analysis procedures, reducing sugars and sucrose follow the method proposed by Apriantono et al., (1994) that is total sugar analyzed using Anthrone method, reducing the sugar by Nelson-Somogyi method, while sucrose content is calculated from total sugar minus reducing sugar multiplied by 0.95 . Samples for analysis of total sugar content, reducing sugars and sucrose also use the terminal leaves of shoots at one time taking. After arriving at the laboratory, samples dried by the oven. After dry samples are stored in the freezer. Analyzes are performed simultaneously after the collection of the samples is completed. $\mathrm{N}$, $\mathrm{P}$, and K Leaves (\%) nutrients analysis N, P and K nutrients using terminal leaf samples are performed in the Soil Laboratory, Faculty of Agriculture, Warmadewa University. The leaf samples were collected in 2 phases of the growth of shoots as described in the analysis of hormonal stages. $\mathrm{N}$ ( $\mathrm{N}$ total) nutrient content was analyzed using the Kjeldahl method, P-available (Olsen and Bray method), K-total ( $\mathrm{HCl} 25 \%$ ) according to Yoshida et al., (1972).

\section{Results and Discussions}

Siam citrus crop Signification of the influence of stem position and observation season on development flowers in the framework of fruit-set formation in Siam citrus plants. Middle and lower trunks show a significant difference, the most formed is the 224.95 (more) 115.74\% upper stem compared to the lower stem: 104.27 (florets), this supported by at least a drop in flowers on the upper stem that is $4.14 \%$ when compared to the rootstock, namely. $12.49 \%$. The average value between the intervening on-season and offseason did not show any significant differences with each number of fall flowers: 152.57 (florets) and 151.44 (florets) 

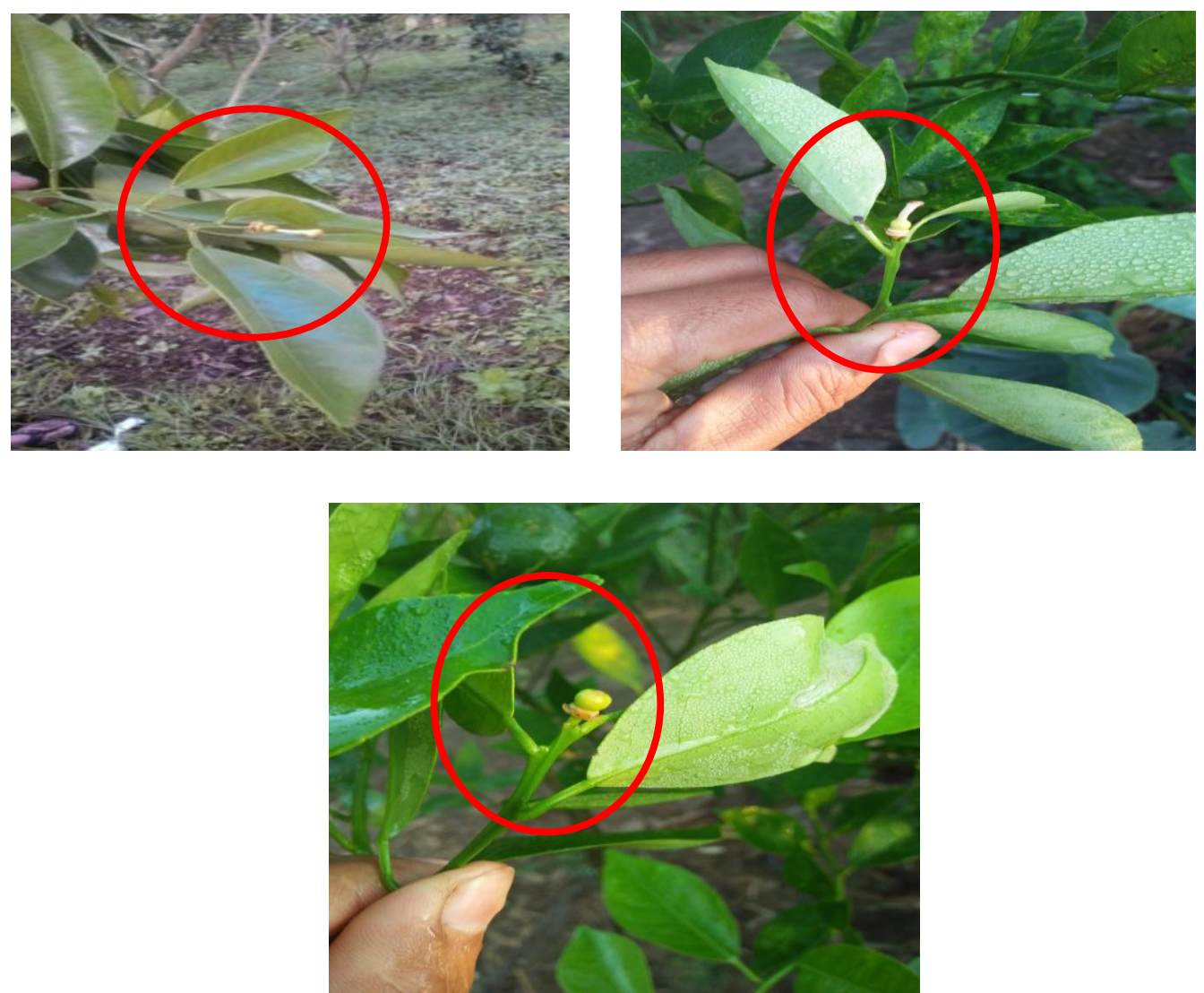

Figure 1. The process of fruit-set development on citrus Siam plant

Table 1

The average number of flowers in bloom, deciduous flowers and flowers is formed when observing the position of the flower's appearance and flowering period on the orange plant

\begin{tabular}{lccc}
\hline \multirow{2}{*}{ Flowering position } & \multicolumn{3}{c}{ Observed variables } \\
\cline { 2 - 4 } & Blooming flower & Fall flower & $\begin{array}{c}\text { Flowers are } \\
\text { formed }\end{array}$ \\
\hline Top stem & $234.57 \mathrm{c}$ & $4,14 \mathrm{c}$ & $224,95 \mathrm{a}$ \\
Middle stem & $143,05 \mathrm{~b}$ & $7,57 \mathrm{a}$ & $130,55 \mathrm{~b}$ \\
rootstock & $114,27 \mathrm{a}$ & $12,49 \mathrm{~b}$ & $104,27 \mathrm{c}$ \\
$\quad$ BNT & 20,60 & 2,63 & 20,91 \\
On-season period & $166,91 \mathrm{a}$ & $9,18 \mathrm{a}$ & $152,57 \mathrm{a}$ \\
Off-season period & $161,02 \mathrm{a}$ & $6,95 \mathrm{a}$ & $151,44 \mathrm{a}$ \\
\multicolumn{1}{c}{ BNT } & 25,23 & 3,22 & 26,00 \\
\hline
\end{tabular}

Statistical analysis showed that the number of flowers blooming on the upper, middle and lower stems showed a significantly different effect, and between the on-season and off-season periods showed an effect that was not significantly different, the interaction between the position of the flower and the flowering season showed a real interaction at the level p 5\% (Table 1).

Statistical analysis showed that the number of flowers blooming on the upper, middle, and lower stems showed a significant difference between the on-season and off-season periods. The effect between the

Sulistiawati, N. P. A. (2018). Flower growth position determines with formation of fruit-set on citrus siam plants. International Journal of Life Sciences, 2(3), 38-47. https://doi.org/10.29332/ijls.v2n3.202 
position of the flower and flowering season showed a real interaction at the level p 5\% (Table 1). The highest average number of blooming flowers is on the upper stem, namely: 234.57 (florets), followed by the middle stem 143.05 (florets), and the least is the rootstock, namely: 114.27 (florets). The number of flowers blooms between the on-season period and the off-season period there are no significant differences, namely: 166.91 (florets) and 161.02 (florets). The parameters of the amount of interest fall from the results of statistical analysis shows the position of the upper stem, middle and the lower stem, as well as the season between onseason and off-season, showed a significant effect $(\mathrm{P}<0.05)$, the interaction between the flower position and the flow period showed an unreal effect $(\mathrm{P} \geq 0.05)$ (Table 1).

The average number of deciduous flowers between the upper, middle and lower stem positions shows a significant difference, most of them are 12.49 (florets) followed by the middle stem, namely: 7.57 (the least florets are the upper stem) that is: 4.14 (florets). The average value between the on-season and off-season periods did not show a significant difference with each number of flowers falling: 9,18 (florets and 6,95 (florets) (Table 1).

Table 2

Average relative water content (RCW) leaves, chlorophyll content, and fruit-set

(\%) formed in the top, middle and lower trunk in the flowering period

\begin{tabular}{llll}
\hline \multicolumn{1}{c}{ Flowering } & \multicolumn{3}{c}{ OBSERVED variables } \\
\cline { 2 - 4 } \multicolumn{1}{c}{ Period } & \multicolumn{1}{c}{ RWC } & \multicolumn{1}{c}{ Chlorophyll } & Fruit-set \\
\hline Top stem & $46,78 \mathrm{a}$ & $75,85 \mathrm{a}$ & $95,75 \mathrm{a}$ \\
Middle stem & $41,76 \mathrm{~b}$ & $22,34 \mathrm{~b}$ & $92,52 \mathrm{a}$ \\
Rootstock & $41,26 \mathrm{~b}$ & $18,64 \mathrm{c}$ & $91,30 \mathrm{a}$ \\
BNT & 3,63 & 1,77 & $3,40 \mathrm{a}$ \\
on-season & $50,04 \mathrm{a}$ & $27,66 \mathrm{a}$ & $93,30 \mathrm{a}$ \\
off-season & $36.62 \mathrm{a}$ & $16,94 \mathrm{a}$ & $93,07 \mathrm{a}$ \\
BNT & 4,44 & 2,16 & \\
\hline
\end{tabular}

Table 3

Average percentage N, P, dan K leaves (\%) formed in the top, middle and lower trunk in the flowering period

\begin{tabular}{llllll}
\hline \multicolumn{1}{c}{ Position Flowering } & \multicolumn{5}{c}{ Observed variables } \\
\cline { 2 - 6 } \multicolumn{1}{c}{ Period } & $\% \mathrm{~N}$ & $\% \mathrm{P}$ & $\% \mathrm{~K}$ & \\
\hline Top stem & $1,40 \mathrm{a}$ & 0,74 & $\mathrm{a}$ & 5,42 & $\mathrm{a}$ \\
Middle stem & $1,22 \mathrm{~b}$ & 1,22 & $\mathrm{~b}$ & 2,70 & $\mathrm{~b}$ \\
Rootstock & $1,16 \mathrm{c}$ & $1,16 \mathrm{~b}$ & 2,17 & $\mathrm{c}$ \\
BNT & 1,72 & 0,15 & & 0,23 & \\
Gadu season & $27,66 \mathrm{a}$ & $27,66 \mathrm{a}$ & 2,52 & $\mathrm{a}$ \\
Cassava season & $16,94 \mathrm{a}$ & $16,94 \mathrm{a}$ & $2,01 \mathrm{a}$ \\
BNT & 2,16 & 2,16 & 0,41 & \\
\hline
\end{tabular}

Percentage of fruit-set formation (\%) The results of statistical analysis show the position of the upper, middle and lower stem, showing an unreal effect on the formation of fruit-set, as well as the development of flowers shows an unreal effect showing unreal effects, and the interaction between the position of the stem and the period of estimation shows influence which is not real $(P \geq 0.05)$ (Table 2). The average percentage of fruit-set in the upper, middle and lower stem positions shows the unreal differences, the most formed fruit-set is 92.75\% upper stem followed by rootstock: $92.52 \%$ ) and at least percentage formed fruit-set is the middle stem, namely: $91.30 \%$. The average value between flowering periods did not show any significant differences with each fruit-set percentage formed: $93.30 \%$ and $93.07 \%$

The interaction between the location of the flower and the planting season showed an unreal effect on the formation of flowers on the orange plant. The number of flowers formed between the position of the upper, 
middle lower trunks shows a significant difference, the most formed is the 224.95 (more) $115.74 \%$ upper stem compared to the lower stem: 104.27 (florets), this supported by at least a drop in flowers on the upper stem that is $4.14 \%$ when compared to the rootstock, namely. $12.49 \%$. The average value between the intervening season and Gadu did not show any significant differences with each number of fall flowers: 152.57 (florets and 151.44 (florets) (Table 4). Naturally, citrus plants are perennial plants that have properties seasonal fruit, ie plants that are in the same environmental conditions but show different flowering behavior may be caused by the existence of endogenous conditions and genetic information on plants that are suppressing and appearing on flower induction.

Seasonal characteristics of fruit plants that occur in tropical climates are caused by some such as low flowering and fertilization efficiency, because of the erratic early fruiting and biennial bearing properties, biennial bearing properties that are unstable or fruitful nature of flowering and fruiting in one year ( on year) and not bear fruit the following season. The success of plants transitioning from the vegetative phase to the reproductive phase depends on the position of the stem of the plant and affects the ability of the plant to induce flowers (Reddy et al., 2014). The results of statistical analysis of the percentage of fruit-set formed shows the position of the upper, middle and lower stem, as well as the season between gadu and cassava showing an unreal effect, There is a correlation between flowering induction and sucrose content of flowering hormone (florigen) or flowering stimulus on leaves which transfers vegetative growth to reproductive growth, (2) optimum nutrient conditions along with changes in apex, and (3) changes in apex which converts and converts nutrients so that flowering induction occurs such as nutria nitrogen, phosphate, and potassium content (Hempel et al., 2000)

\section{Conclusion}

a) The interaction between the position of the stem and the observation of the planting season showed an unreal effect on the formation of the number of flowers and also influenced the percentage of fruit-set formation on Siamese citrus plant

b) The highest fruit-set is found in the upper stem, which is $92.75 \%$ and the lowest is at the lower stem $91.30 \%$, this is supported by the high interest that is formed on the upper stem that is ... more ...\% when compared to the lower stem, namely

\section{Acknowledgments}

Acknowledgment Praise gratitude authors the presence of God all night, so that this simple writing can be solved can finish this paper thanks to some help from:

a) The Rector Warmadewa University for his permission to conduct research

b) The Dean Agriculture Faculty Warmadewa University, the volunteered to provide some facilities so that the research could run.

c) Much obliged for LEMLIT Warmadewa University which has funded Decentralization Research Competitive Grant in 2017. Thanks also go to all those have helped this research4.

d) Thanks to the editor-in-c Thanks to the editor-in-chief of IJLS who has helped in the act of IJLS who has helped in the acceptance of my writing that is still far from perfect all the parties that I cannot mention one by, at the end of the word I say many thanks to all parties.

Sulistiawati, N. P. A. (2018). Flower growth position determines with formation of fruit-set on citrus siam plants. International Journal of Life Sciences, 2(3), 38-47. https://doi.org/10.29332/ijls.v2n3.202 


\section{References}

Ahmed, N., Kumar, D., Mir, J. I., \& Pal, A. A. (2014). Physiology of flowering in perennial temperate fruit crops. In Souvenir, National Seminar-cum-Workshop on Physiology of Flowering in Perennial Fruit Crops (pp. 4849).

Apriyantono, A., D. Fardias, N.L. Puspitasari, Sedarnawati, S. Budiyanto. (1994). Petunjuk Laboratorium Analisis Pangan. Bogor Institut Pertanian Bogor, Fakultas Teknologi Pertanian.

Barendse, W., Vaiman, D., Kemp, S. J., Sugimoto, Y., Armitage, S. M., Williams, J. L., ... \& Band, M. (1997). A medium-density genetic linkage map of the bovine genome. Mammalian Genome, 8(1), 21-28.

Horvath, E., Majlis, S., Rossi, R., Franco, C., Niedmann, J. P., Castro, A., \& Dominguez, M. (2009). An ultrasonogram reporting system for thyroid nodules stratifying cancer risk for clinical management. The Journal of Clinical Endocrinology \& Metabolism, 94(5), 1748-1751.

Kowalska, E., Remita, H., Colbeau-Justin, C., Hupka, J., \& Belloni, J. (2008). Modification of titanium dioxide with platinum ions and clusters: application in photocatalysis. The Journal of Physical Chemistry C, 112(4), 11241131.

Kowalska, G. (2008). Flowering biology of eggplant and procedures intensifying fruit-set. Acta Scientiarum Polonorum, Hortorum Cultus, 7(4), 63-76.

Parvathi, M. S. (2015). Transcriptional regulation to enhance drought tolerance in plants: Co-expression of ahbtf3, ahnf-ya 7 and ecsap-zf in rice and characterization of novel regulator, ectaf6 in model system(doctoral dissertation, university of agricultural sciences gkvk, bengaluru).

Rai, I. N., Semarajaya, C. G. A., \& Wiraatmaja, I. W. (2013). Studi Fenofisiologi Pembungaan Salak Gula Pasir sebagai Upaya Mengatasi Kegagalan Fruit-Set. Jurnal Hortikultura, 20(3).

Reddy, Y. N., \& Bhagwan, A. Induction Of Flowering In Fruit Crops-Physiological And Plant Architectural Implications. Souvenir, 24.

Saro, A., Liu, J., Mohr, J. J., Aird, K. A., Ashby, M. L. N., Bayliss, M., ... \& Carlstrom, J. E. (2014). Constraints on the CMB temperature evolution using multiband measurements of the Sunyaev-Zel'dovich effect with the South Pole Telescope. Monthly Notices of the Royal Astronomical Society, 440(3), 2610-2615.

Sulistiawati Anom, N. P. (1916). Kartini.

Sulistiawati, N. P. A., Kartini, L., \& Yuliartini, M. S. (2017). Identification of Development Phases and Changes Shoots Flowering Orange Siam Plants. International Journal of Life Sciences (IJLS), 1(2), 28-38.

Yoshida, S. (1972). Physiological aspects of grain yield. Annual Review of Plant Physiology, 23(1), $437-464$. 


\section{Biography of Author}

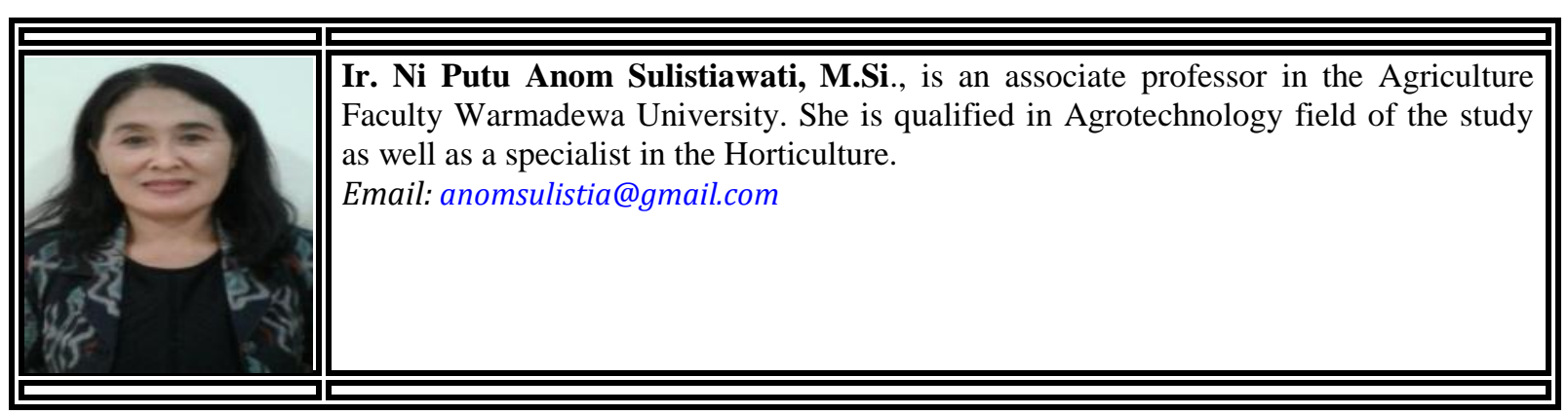

Sulistiawati, N. P. A. (2018). Flower growth position determines with formation of fruit-set on citrus siam plants. International Journal of Life Sciences, 2(3), 38-47. https://doi.org/10.29332/ijls.v2n3.202 